\title{
Short-chain fatty acids can improve lipid and glucose metabolism independently of the pig gut microbiota
}

Hua Zhou ${ }^{1,2}$, Bing Yu ${ }^{1,2}$, Jing Sun ${ }^{3,4}$, Zuohua Liu ${ }^{3,4}$, Hong Chen ${ }^{5}$, Liangpeng Ge ${ }^{3,4^{*}}$ and Daiwen Chen ${ }^{12^{*}}$ (D)

\begin{abstract}
Background: Previous studies have shown that exogenous short-chain fatty acids (SCFAs) introduction attenuated the body fat deposition in conventional mice and pigs. However, limited studies have evaluated the effects of exogenously introduced SCFAs on the lipid and glucose metabolism independently of the gut microbiota. This study was to investigate the effects of exogenous introduction of SCFAs on the lipid and glucose metabolism in a germ-free (GF) pig model.
\end{abstract}

Methods: Twelve hysterectomy-derived newborn pigs were reared in six sterile isolators. All pigs were hand-fed with sterile milk powder for $21 \mathrm{~d}$, then the sterile feed was introduced to pigs for another $21 \mathrm{~d}$. In the second 21-d period, six pigs were orally administrated with $25 \mathrm{~mL} / \mathrm{kg}$ sterile saline per day and considered as the GF group, while the other six pigs were orally administrated with $25 \mathrm{~mL} / \mathrm{kg}$ SCFAs mixture (acetic, propionic, and butyric acids, 45,15 , and $11 \mathrm{mmol} / \mathrm{L}$, respectively) per day and regarded as FA group.

Results: Orally administrated with SCFAs tended to increase the adiponectin concentration in serum, enhance the CPT-1 activity in longissimus dorsi, and upregulate the ANGPTL4 mRNA expression level in colon $(P<0.10)$. Meanwhile, the mRNA abundances of ACC, FAS, and SREBP-1C in liver and CD36 in longissimus dorsi of the FA group were decreased $(P<0.05)$ compared with those in the GF group. Besides, the mRNA expression of $P G C-1 a$ in liver and $L P L$ in longissimus dorsi tended to $(P<0.10)$ upregulate and downregulate respectively in the FA group. Moreover, oral administration of SCFAs tended to increase the protein level of GPR43 $(P<0.10)$ and decrease the protein level of ACC $(P<0.10)$ in liver. Also, oral administration of SCFAs upregulated the P-AMPK/AMPK ratio and the mRNA expressions of GLUT-2 and GYS2 in liver $(P<0.05)$. In addition, the metabolic pathway associated with the biosynthesis of unsaturated fatty acids was most significantly promoted $(P<0.05)$ by oral administration of SCFAs.

Conclusions: Exogenous introduction of SCFAs might attenuate the fat deposition and to some extent improve the glucose control in the pig model, which occurred independently of the gut microbiota.

Keywords: Germ-free, Glucose metabolism, Lipid metabolism, Pig model, Short-chain fatty acids

\footnotetext{
* Correspondence: geliangpeng1982@163.com; dwchen@sicau.edu.cn

${ }^{3}$ Key Laboratory of Pig Industry Sciences, Rongchang 402460, Chongqing,

China

'Key Laboratory of Animal Disease-Resistance Nutrition, Chengdu 611130,

Sichuan, China

Full list of author information is available at the end of the article
}

C The Author(s). 2021 Open Access This article is licensed under a Creative Commons Attribution 4.0 International License, which permits use, sharing, adaptation, distribution and reproduction in any medium or format, as long as you give appropriate credit to the original author(s) and the source, provide a link to the Creative Commons licence, and indicate if changes were made. The images or other third party material in this article are included in the article's Creative Commons licence, unless indicated otherwise in a credit line to the material. If material is not included in the article's Creative Commons licence and your intended use is not permitted by statutory regulation or exceeds the permitted use, you will need to obtain permission directly from the copyright holder. To view a copy of this licence, visit http://creativecommons.org/licenses/by/4.0/ The Creative Commons Public Domain Dedication waiver (http://creativecommons.org/publicdomain/zero/1.0/) applies to the data made available in this article, unless otherwise stated in a credit line to the data. 


\section{Background}

Emerging evidence indicated that gut microbiota plays a critical contributor to the host's health [1]. Noteworthy, the beneficial effects of gut microbiota are at least partly attributed to the short-chain fatty acids (SCFAs), which are the end-products produced from the fermentation of dietary fiber and resistant starch [2, 3]. SCFAs acts as pivotal roles in various biological activities, such as lipid and glucose metabolism [4-6]. Recent studies have reported that oral administration of SCFAs increased the energy expenditure and fat oxidation in obese mice [7], prevented body weight gains, and enhanced insulin sensitivity in high-fat diet-fed mice [8]. Moreover, exogenously introduced SCFAs reduced the fat deposition in weaned and growing pigs by decreasing lipogenesis and promoting lipolysis in different tissues $[9,10]$. Human intervention reports found that SCFAs could regulate whole-body substrates and energy metabolism by increasing fasting fat oxidation and resting energy expenditure [11]. However, controversy still exists considering the role of SCFAs in lipid metabolism. Previous work demonstrated that SCFAs were thought to contribute additional calories in the obese, thus resulting in additional weight gain [12]. Conflicting literature indicated that enhanced acetate turnover aggravated the development of obesity and insulin resistance in rodents [13]. The inconsistent effects of SCFAs on lipid and glucose metabolism might affect by gut microbiota, which plays a vital role in the development and progression of obesity $[14,15]$. It has been observed that the Christensenella genus could prevent weight gain in mice [16], and the Akkermansia genus was reported to correlate with lower visceral fat deposits [17]. Decreased the abundances of Bacteroides and Prevotella were indicated positively correlated with energy intake and adiposity [18]. Moreover, the numbers of microbiota are closely associated with SCFAs concentrations [19]. Thus, gut microbiota may interfere with the effects of exogenous introduction of SCFAs on the host's health, and further well-controlled studies are urgently needed. Germ-free (GF) animals are free from living microorganisms, including bacteria, viruses, fungi, protozoa, and parasites throughout their life, and are reared in sterile environments [20,21]. The domestic pig (Sus scrofa) is a preferable model of human health, which is similar in anatomy, physiology, and genetics to humans $[22,23]$. Accordingly, the pig with an absence of gut microbes is the valid experimental model for dissecting the effects of exogenously introduced SCFAs on lipid and glucose metabolism. Moreover, the systematic crosstalk of exogenous SCFAs and the host's lipid and glucose metabolism has been rarely investigated in the absence of gut microbiota. Therefore, this study was to take biochemistry and metabolomics analysis to explore the effects of oral administration of
SCFAs on the lipid and glucose metabolism in a GF pig model, which may help us to further understand the underlying mechanisms of SCFAs for alleviating fat deposition and promoting the host health.

\section{Materials and methods}

The experiment was conducted at the Experimental Swine Engineering Center of the Chongqing Academy of Animal Sciences (CMA No. 162221340234; Chongqing, China).

\section{Animals}

Twelve neonatal GF pigs were delivered via hysterectomy from four multiparous Bama sows (a native breed of China). On 112 d of gestation (full-term, 114 d), pregnant sows were anesthetized with $4 \%$ isoflurane, and the uterus was excised from the sow and transferred into a sterile isolator (DOSSY Experimental Animals Co., Ltd., Chengdu, China) through a tank containing $120 \mathrm{~L}$ of $0.1 \%$ peracetic acid for decontamination. Then, 12 neonatal pigs (male and female in half) were taken from the uterus and transferred to six rearing isolators (Class Biologically Clean Ltd., Madison, WI, USA). The rearing isolator contains a checkboard, two pigs per isolator, and fed separately. The rearing isolators had been performed by spraying with $1 \%$ peracetic acid in advance and preserved in sterile environments as described previously [21]. The pig's skin, sterile environments, rectal swabs, and oral mucosa were detected via anaerobic (thioglycollate medium) and aerobic (brain heart infusion broth) culture of samples at least every week in accordance with the Chinese National Standard (GB/T 14926-41-2001). Colonic digesta was collected at the end of the experiment for further confirmation of sterile status.

\section{Experimental design and diet}

Among the six rearing isolators, three of them were designated as the FA group, and the other three isolators were treated as the GF group. These pigs in the FA and GF groups were hand-fed ${ }^{60} \mathrm{Co}-\gamma$-irradiated sterile milk powder (Table S1) and diluted with sterile water 1:4 for $21 \mathrm{~d}$. A corn-soybean feed (Table S2) was formulated according to the requirements of Chinese Feeding Standards (2004) for local pigs. It was sterilized by Co60- $\gamma$-radiation and introduced to the GF and FA pigs for another $21 \mathrm{~d}$. In the second $21-\mathrm{d}$ period, the FA group was orally administrated with sterile $25 \mathrm{~mL} / \mathrm{kg}$ SCFAs mixture (acetic, propionic, and butyric acids, 45 , 15 , and $11 \mathrm{mmol} / \mathrm{L}$, respectively) per day, and the GF group was orally administrated with $25 \mathrm{~mL} / \mathrm{kg}$ sterile saline per day. The introduction volume of SCFAs mixture or sterile saline for each pig per day is presented in Table S3. Furthermore, the SCFAs mixture was 
confected in the laminar airflow clean benches, and the acetic, propionic, and butyric acids (analytically pure) was filtered through a $0.22-\mu \mathrm{m}$ membrane and mixing with sterile water. During the two 21-d periods, pigs were allowed ad libitum access to sterile water. To maintain the sterile environment in the present study, when the SCFAs, water, milk, and feed in the rearing isolators were consumed, the replacement containers for sterile SCFAs, water, milk, and feed were delivered into the rearing isolator via the transfer port. Before transferred into the transfer port, the containers were preliminarily decontaminated with $0.5 \%$ peracetic acid and then spraying with $1 \%$ peracetic acid.

\section{Sample collections}

In the morning of $d 42$, blood was drawn from anterior vena cava, centrifuged at 3,000 $\times g$ for $15 \mathrm{~min}$, and stored at $-80^{\circ} \mathrm{C}$ for further measurements. After blooding, pigs were euthanized by isoflurane anesthesia. The abdomen was opened in the laminar airflow clean benches, and the samples of the colon, liver, and longissimus dorsi were immediately collected in liquid nitrogen and stored at $-80^{\circ} \mathrm{C}$ for further analysis.

\section{Serum parameters measurement}

The concentrations of adiponectin, insulin, glucagon, glucagon-like peptide 1 , and leptin in serum were detected by commercial enzyme-linked immunosorbent assay (ELISA) kits from Chenglin Co. Ltd. (Beijing, China) in accordance with the manufacturer's instructions. The levels of total cholesterol (TC), triglyceride (TG), high-density lipoprotein-cholesterol (HDL-c), lowdensity lipoprotein-cholesterol (LDL-c), and glucose in serum were measured using commercial kits (Nanjing Jiancheng Bioengineering Institute, Nanjing, China) following with the manufacturer's instructions. Each parameter was simultaneously measured in triplicate on the same plate. The differences among parallels should be small (coefficient of variation was less than 10\%) to guarantee the reproducibility of repeated measurements.

\section{Determination of enzyme activity}

The frozen sample of the liver and longissimus dorsi (approximately $1.0 \mathrm{~g}$ ) was homogenized in ice-cold saline solution (1:9, wt/vol), centrifuged at 3,000 $\times g$ for $15 \mathrm{~min}$ at $4{ }^{\circ} \mathrm{C}$, and stored at $-80^{\circ} \mathrm{C}$ for further analysis. The activities of carnitine palmitoyltransferase 1 (CPT-1), lipoprotein lipase (LPL), hepatic lipase (HL), and malate dehydrogenase $(\mathrm{MDH})$ in liver and longissimus dorsi were determined using commercial kits (Nanjing Jiancheng Bioengineering Institute, Nanjing, China) in accordance with the manufacturer's instructions. The total protein concentration of liver and longissimus dorsi homogenates was measured by the Bradford brilliant blue method [24]. Each parameter was simultaneously determined in triplicate on the same plate. The differences among parallels should be small (coefficient of variation was less than $10 \%$ ) to guarantee the reproducibility of repeated measurements.

\section{Detection of mRNA expression}

Total RNA was isolated from the frozen colon, liver, and longissimus dorsi using Trizol reagent (TaKaRa) in accordance with the manufacturer's instructions. The purity and concentration of the RNA were detected using a NanoDrop ND-2000 spectrophotometer (NanoDrop, Germany). The $\mathrm{OD}_{260}: \mathrm{OD}_{280}$ ratios ranging from 1.8 to 2.0 in all samples were considered as suitable for further measurement. The integrity of RNA was measured by agarose gel electrophoresis, and the 28S:18S ribosomal RNA band ratio was evaluated to be $\geq 1.8$. RNA was reverse transcribed into cDNA by the PrimeScript ${ }^{\mathrm{TM}} \mathrm{RT}$ reagent kit $(\mathrm{TaKaRa})$ following the manufacturer's guidelines. Primers for the associated genes (Table S4) were designed via Primer 6 software (PREMIER Biosoft International, Palo Alto, CA, USA) and commercially synthesized by Sangon Biotech Ltd. (Shanghai, China). The quantitative real-time PCR was analyzed on an ABI Prism 7000 detection system in a two-step protocol with SYBR Green (Applied Biosystems, Foster City, CA, USA). Each reaction was contained in a volume of $5 \mu \mathrm{L}$ SYBR Premix Ex Taq TM (2x), $1 \mu \mathrm{L}$ cDNA, $0.4 \mu \mathrm{L}$ of each forward and reverse primer, $0.2 \mu \mathrm{L}$ ROX reference dye $(50 x)$, and $3 \mu \mathrm{L}$ PCR-grade water. The PCR conditions were the initial denaturation at $95^{\circ} \mathrm{C}$ for $30 \mathrm{~s}$, followed by 40 cycles of denaturation at $95^{\circ} \mathrm{C}$ for $10 \mathrm{~s}$, then annealing at $60^{\circ} \mathrm{C}$ for $25 \mathrm{~s}$, and a $72^{\circ} \mathrm{C}$ extension step for $5 \mathrm{~min}$. The melting curve was formed following each quantitative real-time PCR determination to verify the specificity of the reactions. $\beta$-actin (housekeeping gene) was selected as the reference gene to normalize the mRNA expression of target genes. Gene abundance values of the replicate samples were computed by the $2^{-\Delta \Delta C T}$ method [25]. The relative abundance of the target genes in the GF group was treat a to be 1.0. Each sample was determined in triplicate.

\section{Determination of protein levels}

The antibodies against the $\beta$-actin, GPR43, p-AMPK, AMPK, CPT-1B, and ACC were brought from Abcam (Cambridge, MA, USA), Cell Signaling Technology (Davers, MA), and Santa Cruz Biotechnology Inc. (Santa Cruz, CA, USA), respectively. Protein levels for the $\beta$ actin, GPR43, p-AMPK, AMPK, CPT-1B, and ACC in the liver were measured by western blot analysis in accordance with the instructions described by Suryawan et al. [26]. 


\section{Ultrahigh-performance liquid chromatography equipped with quadrupole time of flight mass spectrometry (UHPLC-Q-TOF/MS) analysis}

Serum samples were separated by the ultra-highperformance liquid chromatography (UHPLC) system (Agilent 1290, Agilent Technologies, Palo Alto, USA) incorporating a hydrophilic interaction liquid chromatography (HILIC) column $(2.1 \mathrm{~mm} \times 100 \mathrm{~mm}, \quad 1.7 \mu \mathrm{m}$; Waters, Milford, MA, USA). The samples were analyzed using a triple time-of-flight (TOF) mass spectrometer (ESI/Triple TOF 5600; AB Sciex, Concord, Canada) equipped with an electrospray ionization source used in positive and negative ion modes. The pretreatment, extraction, and identification of serum samples were according to the procedure described by $\mathrm{Hu}$ et al. [27]. The raw data (whiff scan files) were converted into mzXML format using ProteoWizard [28] and were imported to the XCMS software for peak matching, retention time alignment, and peak area extraction [29]. Metabolite structure identification was performed by comparing the accuracy of $\mathrm{m} / \mathrm{z}$ values $(<25 \mathrm{ppm})$, and MS/MS spectra were interpreted with an in-house database (Shanghai Applied Protein Technology Co. Ltd., China) established with authentic standards. For the XCMS data, the ion peaks that were missing values greater than $50 \%$ in the group were filtered and excluded and data were normalized to total peak intensity. Then, the pattern recognition was analyzed by SIMCA-P software (version 14.1, Umetrics, Umea, Sweden), where could performed to multivariate data measurement, including unsupervised principal component analysis (PCA), supervised partial least squares discriminant analysis (PLS-DA), and supervised orthogonal partial least squares discriminant analysis (OPLS-DA), which were carried out to uncover and extract the statistically significant metabolite variations. The PLS-DA and OPLSDA models were validated based on multiple correlation coefficient $\left(\mathrm{R}^{2}\right)$ and forecast ability according to the model $\left(\mathrm{Q}^{2}\right)$ in cross-validation and permutation test by applying 200 iterations [30]. The $R^{2}$ value in the permutated plot described how well the data fit the derived model, whereas the $\mathrm{Q}^{2}$ value described the predictive ability of the constructed model and was a measure of model quality [31]. Volcano Plot measurement synthesized $t$-test and Fold Change (FC) evaluation were to help identify potential metabolites. Metabolites with the highest variable importance in the projection (VIP) score are the most powerful group discriminators, VIP score > 1 are significant [32]. The significantly differential metabolites were ranked using the VIP score $(>1)$ based on the OPLS-DA model and $P<0.10$. The instructions of metabolites identification and Kyoto Encyclopedia of Genes and Genomes (KEGG) pathway analysis were according to Wang et al.[30].

\section{Statistical analysis}

Data were analyzed in SAS 9.2 (SAS Institute, Inc., Cary, NC, USA) and analyzed using Student's $t$-test, and presented as means \pm SEMs. The individual pig was the statistical unit. $P<0.05$ was considered to be statistically significant, and tendency was declared with $0.05<P<$ 0.10 .

\section{Results}

There were no differences in growth performance, nutrient digestibility, and relative organs weight between the GF and FA groups [33].

\section{Serum parameters}

The impacts of oral administration of SCFAs on the serum parameters are shown in Table 1. Compared with the GF group, the FA group tended to had a higher adiponectin concentration in the serum $(P<0.10)$.

\section{Activities of enzymes in the liver and longissimus dorsi} The activities of enzymes in the liver and longissimus dorsi are presented in Table 2. The activity of CPT-1 in the longissimus dorsi of the FA group was tended to be higher than that in the GF group $(P<0.10)$.

\section{Relative mRNA expressions of lipid metabolism-related genes in liver and longissimus dorsi}

As shown in Table 3, the mRNA expressions of ANGP TL4 in the colon and PGC-1 $\alpha$ in the liver of the FA group tended to upregulate $(P<0.10)$ compared with those in the GF group. Moreover, the mRNA abundances of $A C C, F A S$, and SREBP-1C in the liver of the FA group were lower than those in the GF group $(P<$ $0.05)$. As presented in Table 4, oral administration of SCFAs decreased the mRNA expression of CD36 $(P<$

Table 1 Effects of exogenously introduced SCFAs on the serum parameters in GF pigs ${ }^{\text {a }}$

\begin{tabular}{llll}
\hline Items & GF & FA & $P$-value \\
\hline Adiponectin, $\mu \mathrm{g} / \mathrm{L}$ & $74.48 \pm 1.62$ & $80.63 \pm 2.32$ & 0.06 \\
Glucagon, $\mathrm{pg} / \mathrm{mL}$ & $28.01 \pm 1.52$ & $30.06 \pm 1.23$ & 0.12 \\
GLP-1, pmol/L & $2.51 \pm 0.06$ & $2.57 \pm 0.08$ & 0.52 \\
Insulin, $\mathrm{mIU} / \mathrm{L}$ & $10.20 \pm 0.38$ & $10.76 \pm 0.52$ & 0.40 \\
Leptin, $\mathrm{ng} / \mathrm{L}$ & $1403.2 \pm 38.30$ & $1368.4 \pm 45.03$ & 0.57 \\
$\mathrm{TC}, \mathrm{mmol} / \mathrm{L}$ & $1.45 \pm 0.10$ & $1.59 \pm 0.11$ & 0.38 \\
$\mathrm{TG}, \mathrm{mmol} / \mathrm{L}$ & $0.30 \pm 0.03$ & $0.50 \pm 0.12$ & 0.15 \\
$\mathrm{HDL}, \mathrm{mmol} / \mathrm{L}$ & $0.73 \pm 0.08$ & $0.80 \pm 0.06$ & 0.51 \\
$\mathrm{LDL}, \mathrm{mmol} / \mathrm{L}$ & $0.77 \pm 0.05$ & $0.81 \pm 0.06$ & 0.65 \\
Glucose, mmol/L & $5.31 \pm 0.31$ & $5.33 \pm 0.58$ & 0.97
\end{tabular}

${ }^{a}$ GF germ-free, $F A$ short-chain fatty acids, GLP-1 Glucagon like peptide 1, TC total cholesterol, $T G$ triglyceride, HDL-c high-density lipoprotein-cholesterol, $L D L-c$ low-density lipoprotein-cholesterol. Values are means \pm SEMs, $n=6 /$ group 
Table 2 Effects of exogenously introduced SCFAs on the activities associated with lipids metabolism in liver and longissimus dorsi of GF pigs ${ }^{\text {a }}$

\begin{tabular}{llll}
\hline Items & GF & FA & $P$-value \\
\hline Liver & & & \\
CPT-1, U/mg protein & $192.40 \pm 3.58$ & $191.6 \pm 7.27$ & 0.92 \\
LPL, U/mg protein & $0.75 \pm 0.02$ & $0.73 \pm 0.10$ & 0.86 \\
HL, U/mg protein & $0.77 \pm 0.11$ & $0.78 \pm 0.06$ & 0.97 \\
MDH, U/mg protein & $43.56 \pm 3.93$ & $41.62 \pm 2.48$ & 0.68 \\
Longissimus dorsi & & & \\
CPT-1, U/mg protein & $197.70 \pm 5.92$ & $209.90 \pm 1.91$ & 0.08 \\
LPL, U/mg protein & $0.66 \pm 0.26$ & $0.34 \pm 0.05$ & 0.28 \\
HL, U/mg protein & $0.48 \pm 0.05$ & $0.39 \pm 0.04$ & 0.21 \\
MDH, U/mg protein & $4.08 \pm 0.32$ & $3.41 \pm 0.16$ & 0.10 \\
\hline
\end{tabular}

${ }^{a}$ GF germ-free, $F A$ short-chain fatty acids, CPT-1 carnitine palmitoyltransferase 1, LPL lipoprotein lipase, $H L$ hepatic lipase, $M D H$ malate dehydrogenase. Values are means \pm SEMs, $n=6 /$ group

$0.05)$ and tended to downregulate the mRNA expression of $L P L(P<0.10)$ in the longissimus dorsi.

\section{Relative mRNA expressions of glucose metabolism-related} genes in liver and longissimus dorsi

As presented in Table 5, the oral administration of SCFAs upregulated the mRNA expressions of GLU-2 and GYS2 in the liver $(P<0.05)$. In addition, the mRNA

Table 3 Effects of exogenously introduced SCFAs on the mRNA abundances for key factors associated with lipid metabolism in colon and liver of GF pigs ${ }^{a}$

\begin{tabular}{llll}
\hline Items & GF & FA & $P$-value \\
\hline Colon & & & \\
ANGPTL4 & $1.00 \pm 0.13$ & $1.48 \pm 0.17$ & 0.06 \\
PPAR- $y$ & $1.00 \pm 0.07$ & $0.95 \pm 0.14$ & 0.75 \\
Liver & & & \\
ACC & $1.00 \pm 0.17$ & $0.63 \pm 0.05$ & $<0.01$ \\
FAS & $1.00 \pm 0.16$ & $0.56 \pm 0.03$ & 0.03 \\
CD36 & $1.00 \pm 0.25$ & $0.60 \pm 0.17$ & 0.19 \\
LPL & $1.00 \pm 0.11$ & $0.69 \pm 0.13$ & 0.11 \\
SREBP-1C & $1.00 \pm 0.09$ & $0.72 \pm 0.08$ & 0.04 \\
PPKAA1 & $1.00 \pm 0.10$ & $1.10 \pm 0.09$ & 0.47 \\
PPKAA2 & $1.00 \pm 0.13$ & $0.99 \pm 0.08$ & 0.95 \\
CPT-1B & $1.00 \pm 0.14$ & $0.98 \pm 0.11$ & 0.93 \\
PGC-1a & $1.00 \pm 0.16$ & $2.02 \pm 0.43$ & 0.06 \\
PNPLA2 & $1.00 \pm 0.11$ & $0.86 \pm 0.15$ & 0.47 \\
\hline
\end{tabular}

a GF germ-free, FA short-chain fatty acids, ANGPTL4 angiopoietin-like 4, PPAR- $\gamma$ peroxisome proliferator-activated receptor gamma, ACC acetyl-CoA carboxylase, FAS fatty acid synthase, CD36 fatty acid transporter CD36, LPL lipoprotein lipase, SREBP-1C sterol regulatory element binding protein $1 C$, PRKAA1 AMP activated alpha 1, PRKAA2 AMP activated alpha 2, CPT-1B carnitine palmitoyltransferase $1 \mathrm{~B}, P G C$-1 a peroxisome proliferator-activated receptor gamma coactivator-1a, PNPLA2 patatin-like phospholipase domaincontaining protein 2 . Values are means \pm SEMs, $n=6 /$ group
Table 4 Effects of exogenously introduced SCFAs on the mRNA abundances for key factors associated with lipid metabolism in longissimus dorsi of GF pigs ${ }^{\text {a }}$

\begin{tabular}{llll}
\hline Items & GF & FA & $P$-value \\
\hline ACC & $1.00 \pm 0.14$ & $0.79 \pm 0.03$ & 0.19 \\
FAS & $1.00 \pm 0.33$ & $0.68 \pm 0.06$ & 0.37 \\
CD36 & $1.00 \pm 0.07$ & $0.71 \pm 0.06$ & 0.02 \\
LPL & $1.00 \pm 0.09$ & $0.81 \pm 0.04$ & 0.08 \\
SREBP-1C & $1.00 \pm 0.18$ & $0.65 \pm 0.06$ & 0.11 \\
PPKAA1 & $1.00 \pm 0.08$ & $0.91 \pm 0.07$ & 0.44 \\
PPKAA2 & $1.00 \pm 0.03$ & $1.07 \pm 0.06$ & 0.39 \\
CPT-1B & $1.00 \pm 0.15$ & $1.14 \pm 0.10$ & 0.44 \\
PGC-1a & $1.00 \pm 0.08$ & $1.58 \pm 0.39$ & 0.19 \\
PNPLA2 & $1.00 \pm 0.16$ & $0.97 \pm 0.14$ & 0.90 \\
\hline
\end{tabular}

${ }^{a}$ GF germ-free, FA short-chain fatty acids, ACC acetyl-CoA carboxylase, FAS fatty acid synthase, $C D 36$ fatty acid transporter CD36, $L P L$ lipoprotein lipase, SREBP-1C sterol regulatory element binding protein 1C, PRKAA1 AMP activated alpha 1, PRKAA2 AMP activated alpha 2, CPT-1B carnitine palmitoyltransferase 1 $\mathrm{B}, P G C$-1 a peroxisome proliferator-activated receptor gamma coactivator-1a, PNPLA2 patatin-like phospholipase domain-containing protein 2 . Values are means \pm SEMs, $n=6$ /group

abundances of genes related to glucose metabolism in the longissimus dorsi were no differences between the FA and GF groups $(P>0.10)$ (Table 6).

\section{The protein level associated with lipid metabolism}

As presented in Fig. 1, oral administration of SCFAs tended to increase the protein level of GPR43 $(P<0.10)$ and tended to decrease the protein level of ACC $(P<0.10)$, while upregulated the $\mathrm{p}$-AMPK/AMPK ratio $(P<0.05)$ in the liver.

\section{Metabolomic profile in the serum}

To further evaluate the differences in metabolic profiles related to lipid and glucose metabolism between GF and FA groups, UHPLC-QTOF-MS was used to identify the

Table 5 Effects of exogenously introduced SCFAs on the mRNA abundances for key factors associated with glucose metabolism in liver of GF pigs ${ }^{\text {a }}$

\begin{tabular}{llll}
\hline Items & GF & FA & $P$-value \\
\hline FOXO-1 & $1.00 \pm 0.05$ & $1.09 \pm 0.04$ & 0.22 \\
INSR & $1.00 \pm 0.06$ & $0.81 \pm 0.06$ & 0.16 \\
INS1 & $1.00 \pm 0.10$ & $1.02 \pm 0.04$ & 0.80 \\
PIK3 & $1.00 \pm 0.09$ & $0.72 \pm 0.02$ & 0.12 \\
GLU-2 & $1.00 \pm 0.12$ & $0.58 \pm 0.08$ & $<0.01$ \\
PCK1 & $1.00 \pm 0.05$ & $1.08 \pm 0.01$ & 0.14 \\
GSK3 & $1.00 \pm 0.04$ & $1.10 \pm 0.05$ & 0.17 \\
GYS2 & $1.00 \pm 0.01$ & $1.67 \pm 0.20$ & $<0.01$ \\
\hline
\end{tabular}

a GF germ-free, FA short-chain fatty acids, FOXO-1 foxo1 forkhead box 01, INSR insulin receptor, IRS1 insulin receptor substrate 1, PIK3 phosphatidylinositol 3kinase catalytic subunit type 3, GLU-2 glucose transporter 2, PCK1 phosphoenolpyruvate carboxykinase 1, GSK3 glycogen synthase kinase 3, GYS2 glycogen synthase 2 . Values are means \pm SEMs, $n=6$ /group 
Table 6 Effects of exogenously introduced SCFAs on the mRNA abundances for key factors associated with glucose metabolism in longissimus dorsi of GF pigs ${ }^{\text {a }}$

\begin{tabular}{llll}
\hline Items & GF & FA & $P$-value \\
\hline FOXO-1 & $1.00 \pm 0.44$ & $1.35 \pm 0.34$ & 0.20 \\
Sirt1 & $1.00 \pm 0.02$ & $0.86 \pm 0.03$ & 0.11 \\
INSR & $1.00 \pm 0.09$ & $0.99 \pm 0.21$ & 0.97 \\
INS1 & $1.00 \pm 0.15$ & $1.08 \pm 0.09$ & 0.64 \\
PIK3 & $1.00 \pm 0.09$ & $0.96 \pm 0.07$ & 0.73 \\
GSK3 & $1.00 \pm 0.04$ & $1.01 \pm 0.08$ & 0.91 \\
\hline
\end{tabular}

a GF germ-free, FA short-chain fatty acids, FOX-1 foxo1 forkhead box 01, Sirt1 silent information regulator 1, INSR insulin receptor, IRS1 insulin receptor substrate 1, PIK3 phosphatidylinositol 3-kinase catalytic subunit type 3, GSK3 glycogen synthase kinase 3 . Values are means \pm SEMs, $n=6 /$ group

differential metabolites. Serum samples from GF and FA pigs were measured in both positive and negative ionization modes. The PCA, PLS-DA, and OPLS-DA were performed to visualize the LC-MS dataset and exhibit the differences and similarities among the samples. No marked difference between GF and FA groups in PCA analysis (Fig. 2a, b). To further dissect the difference between GF and FA groups, the PLS-DA and OPLS-DA analyses were employed. The PLS-DA (Fig. 2c, d) and OPLS-DA (Fig. 2e, f) score plots show separation between the GF and FA groups in both positive and negative modes. As presented in Fig. 3, the differential metabolites change between GF and FA groups were exhibited by univariate measurement. The red dots exhibit metabolites that differed between GF and FA groups undertaking $\mathrm{FC}>1.5$ and $P$-value $<0.05$. To assess which compounds were responsible for the differences between the two groups, the parameters of VIP $>$ 1.0 and adjusted $P<0.10$ were used as key lineages for separating the serum compounds between GF and FA groups (Fig. 4 and Table 7). In total, 33 compounds with a VIP $>1.0$ and adjusted $P<0.10$ were identified. Among these, 17 metabolites (choline, hypoxanthine, glycerophosphocholine, N1-methyl-2-pyridone-5-carboxamide, $L$-malic acid, 1-oleoyl- $L$-alpha-lysophosphatidic acid, arachidonic acid, stearic acid, ketoisocaproic acid, hypoxanthine, 9R-10S-EpOME, phosphorylcholine, succinate, docosahexaenoic acid, docosatrienoic acid, and palmitic acid) were enriched $(P<0.05)$ and four metabolites $(D$ mannose, $L$-pyroglutamic acid, 4-nitrophenol, and stavudine) were reduced $(P<0.05)$ in the FA group compared with those in the GF group. Overall, these results suggested that oral administration of SCFAs markedly increased the lipids related compounds (arachidonic acid, stearic acid, docosahexaenoic acid, palmitic acid, glycerophosphocholine), indicating that exogenous SCFAs had a strong impact on the lipid metabolism in pigs. To further understand the physiological difference induced by oral administration of SCFAs, the KEGG pathway database was used to identifying associated metabolic pathways of 33 metabolites detected in serum. According to Fig. 5, these compounds were involved in several biochemical pathways, and the biosynthesis of unsaturated fatty acids pathway was most significantly affected $(P<$ 0.05 ) by exogenous SCFAs.

\section{Discussion}

As is known to us, increasing dietary fiber intake contributes greatly to body weight and glucose tolerance [34]. Notably, when introduced with SCFAs, the SCFAs concentrations in the circulation or gut were similar to those observed in a higher fiber diet [35]. Indeed, it has been reported that exogenous introduction of SCFAs attenuated the body fat deposition in both mice, pigs, and humans [7, 10, 11]. Although SCFAs can prevent fat accumulation, while the underlying mechanisms are still
A

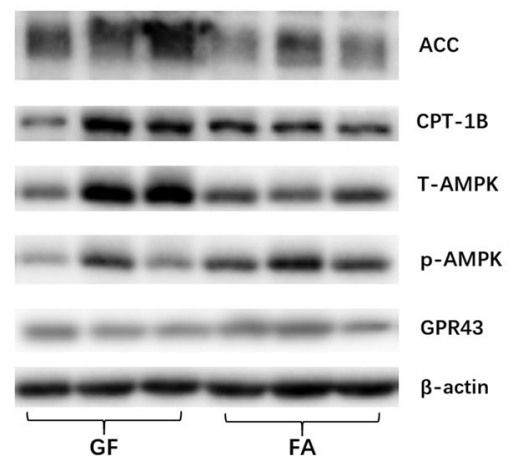

B

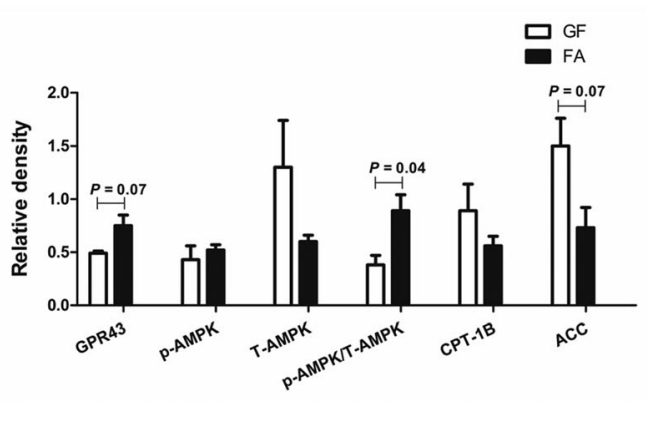

Fig. 1 Effects of exogenously introduced SCFAs on the protein levels of GPR43, p-AMPK, AMPK, CPT-1B, and ACC in the liver of GF pigs. GF, germ-free; FA, short chain fatty acids; ACC, acetyl-CoA carboxylase; CPT-1B, carnitine palmitoyltransferase 1 B; p-AMPK, phosphorylated adenosine monophosphate-activated protein kinase; AMPK, adenosine monophosphate-activated protein kinase; GPR43, G-protein-coupled receptors 43 
Chou et al. Journal of Animal Science and Biotechnology

(2021) 12:61

Page 7 of 14
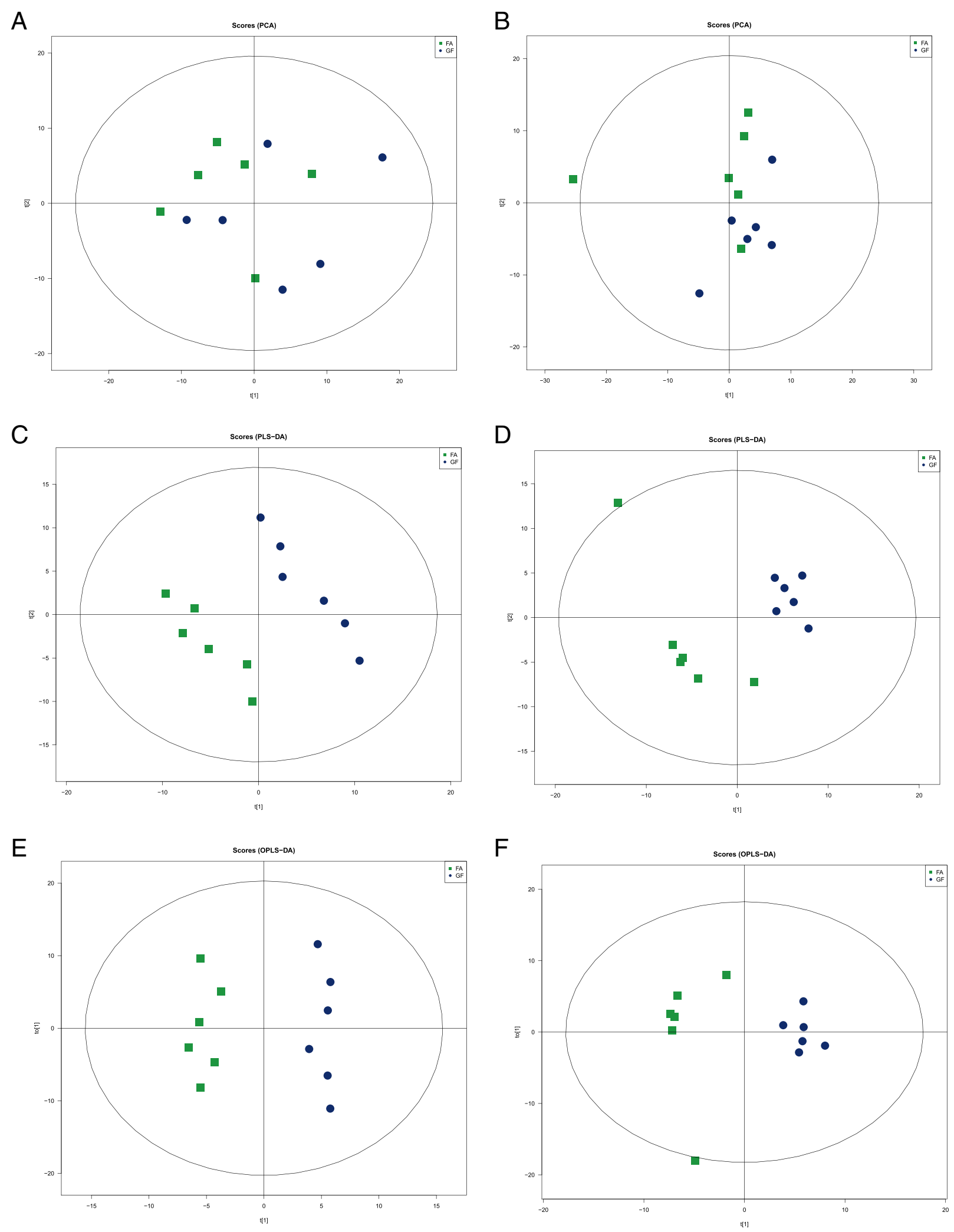

Fig. 2 (See legend on next page.) 
(See figure on previous page.)

Fig. 2 The PCA, PLS-DA, and OPLS-DA score plots comparing GF (blue rotundities) and FA (green squares) pigs in positive electrospray ionization mode $\left(\mathrm{ESI}^{+}\right)$and negative electrospray ionization mode $\left(\mathrm{ESI}^{-}\right)$metabolomics profiles of serum. Panels $\mathbf{a}\left(\mathrm{ESI}^{+}\right)$and $\mathbf{b}\left(\mathrm{ESI}^{-}\right)$are PCA score plots. Panels c (ESI $\left.{ }^{+}, R^{2} X=0.459, R^{2} Y=0.996, Q^{2}=0.649\right)$ and $\mathbf{d}\left(E S I^{-}, R^{2} X=0.514, R^{2} Y=0.999, Q^{2}=0.818\right)$ are PLS-DA score plots. Panels e (ESI ${ }^{+}, R^{2} X=$ $\left.0.317, R^{2} Y=0.976, Q^{2}=0.009\right)$ and $\mathbf{f}\left(E S I^{-}, R^{2} X=0.307, R^{2} Y=0.926, Q^{2}=0.201\right)$ are OPLS-DA score plots. GF, germ-free; FA, short chain fatty acids; PCA, principal component analysis; PLS-DA, Partial least squares discriminant; OPLS-DA, orthogonal partial least-squares discriminant

not fully understood. SCFAs can be produced naturally by host metabolic pathways particularly in the liver, but the major site of SCFAs production is the colon which requires the presence of specific bacteria [36]. Moreover, the numbers and diversity of microbiota are positively associated with SCFAs concentrations [19], and several specific microbes species were closely related to host lipid metabolism $[16,17]$. However, whether the SCFAs regulate lipid and glucose metabolism independent of the gut microbiota are largely unknown. Therefore, this study was conducted to explore the effects of exogenous introduction of SCFAs on lipid and glucose metabolism in a GF pig model and to further dissect the underlying mechanisms of exogenously introduced SCFAs on the host's health. To determine the concentration and dose of the SCFAs mixture used in the present experiment, we conducted a preliminary experiment on the conventional Bama piglets $(n=12)$. In the preliminary trial, when pigs fed with $1.25 \mathrm{~S}_{0}$ (acetic, propionic, and butyric acids, 75,25 , and $19 \mathrm{mmol} / \mathrm{L}$, respectively) and $25 \mathrm{~mL} / \mathrm{kg}$ or $1.0 \mathrm{~S}_{0}$ (acetic, propionic, and butyric acids, 60,20 , and $15 \mathrm{mmol} / \mathrm{L}$, respectively) and $25 \mathrm{~mL} / \mathrm{kg}$ SCFAs mixture led to diarrhea and death. Meanwhile, the feed intake was not decreased and without diarrhea after $7 \mathrm{~d}$ when pigs fed with $0.75 \mathrm{~S}_{0}$ (acetic, propionic, and butyric acids, 45,15 , and $11 \mathrm{mmol} / \mathrm{L}$, respectively) and $25 \mathrm{~mL} / \mathrm{kg}$ SCFAs mixture. However, when pigs fed with $0.75 \mathrm{~S}_{0}$ and $35 \mathrm{~mL} / \mathrm{kg}$ SCFAs also led to diarrhea and reduced feed intake. Taken together, we determined the mixture concentrations of acetic, propionic, and butyric acids at
45,15 , and $11 \mathrm{mmol} / \mathrm{L}$, respectively, and a dose of 25 $\mathrm{mL} / \mathrm{kg}$ in the present study.

Acting in peripheral tissues, adiponectin could regulate lipid metabolism and promote energy expenditure [37]. Serum adiponectin concentration was reduced in individuals with obesity and obesity-related diseases [38]. In the present study, oral administration of SCFAs tended to increase the concentration of adiponectin in serum. CPT-1 is the rate-limiting enzyme that determines fatty acids oxidation [39]. ANGPTL4 is a valid inhibitor of lipoprotein lipase to regulate cellular uptake of triglycerides and promote fatty acids oxidation [40, 41]. In our study, oral administration of SCFAs tended to increase the activity of CPT-1 in longissimus dorsi and the mRNA abundance of ANGPTL4 in colon. Meanwhile, we found the mRNA expressions of FAS, ACC, and SREBP-1C in liver of the FA group markedly downregulated compared with those in the GF group. Consistently, previous studies reported similar results in liver, longissimus dorsi, and adipose tissues of conventional pigs $[9,10,42]$. Notably, FAS is the pivotal enzyme that catalyzes fatty acids synthesis [43]. ACC modulates fatty acids metabolism, and its product (e.g. malonyl-CoA) serves as a building block for de novo fatty acids synthesis [44]. The SREBPS increases the transcription of genes that encode the enzymes of fatty acids biosynthesis and cholesterol uptake [45]. In addition, the current study observed the mRNA abundance of $C D 36$ was apparently decreased, and $L P L$ tended to be reduced in longissimus dorsi of the FA group. $L P L$ catalyzes the hydrolysis of
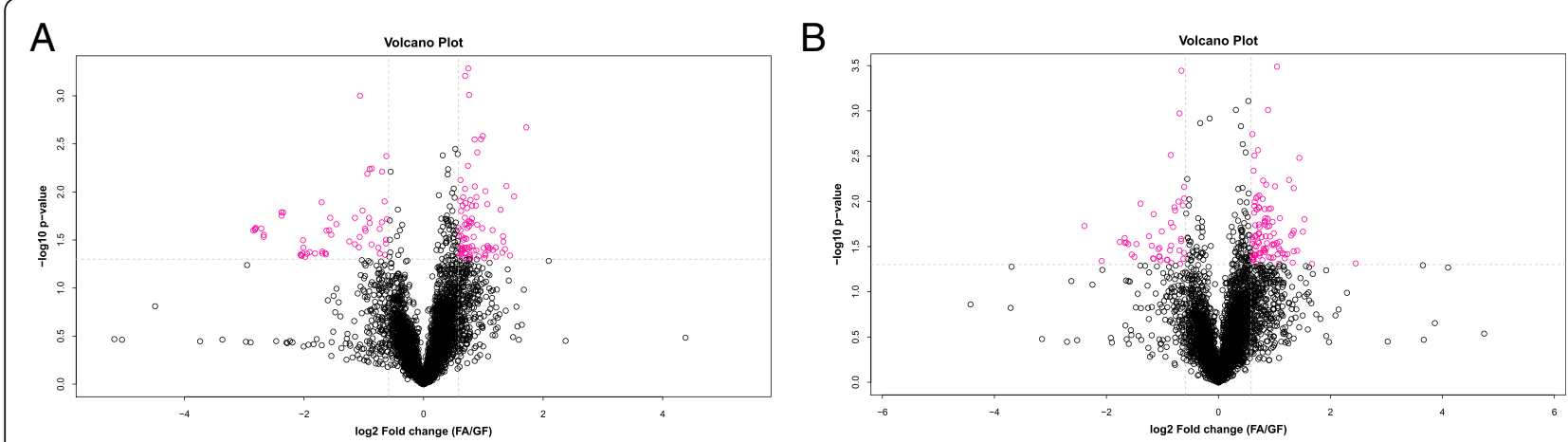

Fig. 3 Volcano plots showing the distribution of all metabolites based on their fold-change values (X-axis, on a logarithmic scale), $P$-value ( $Y$-axis, on a logarithmic scale). Panel a is ESI ${ }^{+}$, Panel $\mathbf{b}$ is $\mathrm{ESI}^{-}$, respectively (FC> 1.50 and $P$-value $\left.<0.05\right)$. GF, germ-free; FA, short chain fatty acids 

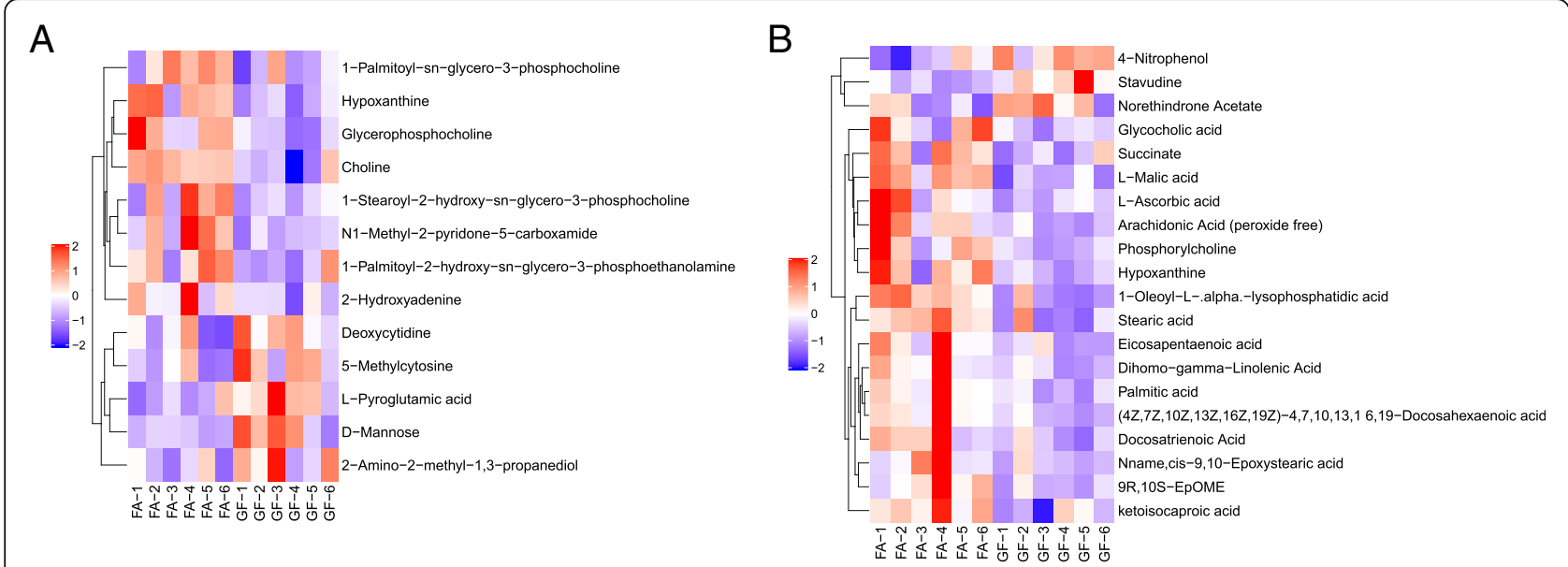

Fig. 4 Hierarchical clustering heat map of significantly differential metabolites from serum of pigs in the $\mathrm{ESI}^{+}$(a) and $\mathrm{ESI}^{-}$(b). Metabolites peak area were Z score transformed. Warm color and cold color indicate increased and decreased expression of the metabolites, respectively. GF, germ-free; FA, short chain fatty acids

triglycerides residing in chylomicrons and providing free fatty acids for tissue utilization [39]. CD36, the fatty acids translocase, regulates the uptake of long-chain fatty acids into cells [46], and elevated expression of CD36 in various tissues resulted in lipid overload and lipotoxicity [47]. Noteworthy, the $P G C-1 \alpha$ was measured as a vital regulator of fatty acids metabolism [48], and increasing the $P G C-1 \alpha$ expression in liver was a negative association with body fat [49]. In the present study, oral administration of SCFAs tended to upregulate the mRNA expression of $P G C-1 \alpha$ in liver, in agreement with the previous studies in conventional pigs and mice $[7,10]$. Besides, SCFAs have been demonstrated to enhance the rates of oxygen consumption, and to increase both fat oxidation and adaptive thermogenesis in rodents $[7,50]$. Collectively, these demonstrated that exogenous SCFAs may decrease the lipid deposition by downregulating the mRNA expressions of genes related to fatty acids synthesis and enhancing energy expenditure in the liver and longissimus dorsi of GF pigs.

The liver also plays a central role in regulating blood glucose homeostasis by uptake of glucose in the postprandial state and conversion to glycogen and triglyceride, and via the production of glucose in the postabsorptive state through glycogenolysis and gluconeogenesis $[51,52]$. The rate-limiting enzyme for glycogen synthesis is glycogen synthase (GS), in mammals, there are two GS isoforms: muscle GS (encoded by GYS1) is abundantly expressed in skeletal and cardiac muscles, and the liver-restricted isoform (encoded by GYS2) [53]. Previous work indicated that mice lacked GYS2 had a severe decrease in their ability to store glycogen in hepatocytes [53]. It is well exhibited that insulin resistance and hepatic steatosis lead to compromised glycogen synthesis [54]. On the contrary, an increase in liver glycogen synthesis directly associated with improved glucose tolerance [55]. In the present study, oral administration of SCFAs significantly increased the mRNA expression of GYS2 in the liver. Similarly, it has been shown that SCFAs supplementation reduced adiposity and improved glucose homeostasis compared to the control group [56]. The GLUT-2 transports glucose in the liver to pass the membrane in a bidirectional way for glycolysis and gluconeogenesis and was identified as a major contributor to glucose and fructose homeostasis in the liver [57]. The increase in the expression of GLUT-2 in liver may be associated with insulin resistance and type-2 diabetes mellitus [58]. In the current study, we found that oral administration of SCFAs markedly downregulated the mRNA abundance of GLU-2 in liver. These suggested that exogenous SCFAs may improve glucose control in the liver of GF pigs.

Although previous scientists had done much work, the underlying mechanisms of SCFAs on lipid and glucose metabolism are still not fully understood. G-proteincoupled receptors (GPRs), GPR41 and GPR43 have been demonstrated to be indispensable for a range of SCFAmediated effects $[59,60]$. SCFAs have been shown to promote energy consumption and fat combustion by activating the GPRs [61]. Meanwhile, it has been indicated that GPR43 knockout mice exhibited a reduction in energy expenditure, while overexpression of GPR43 exhibited an increase in energy expenditure [62]. Moreover, the effects of SCFAs involving improvement of insulin response are also regulated by GPR43, which induces enhanced glucose control [63]. In our study, we observed the protein expression level of GPR43 in liver of the FA group tended to be upregulated compared with that in the GF group. In addition to the SCFAs-GPRs 
Table 7 Altered metabolites in the serum between FA and GF groups ${ }^{a}$

\begin{tabular}{|c|c|c|c|c|c|c|c|}
\hline Adduct & Metabolites & Metabolic pathway & $\begin{array}{l}\text { M-to- } \\
Z\end{array}$ & $\mathrm{Rt}, \mathrm{s}$ & VIP & FC & $\begin{array}{l}P \text { - } \\
\text { value }\end{array}$ \\
\hline$\overline{M+}$ & Choline & Glycerophospholipid metabolism & 104.11 & 559.22 & 3.47 & 1.25 & 0.0042 \\
\hline$(M+H)+$ & Hypoxanthine & Purine metabolism & 137.05 & 349.60 & 6.37 & 1.33 & 0.0058 \\
\hline $\mathrm{M}+$ & Glycerophosphocholine & Glycerophospholipid metabolism & 258.11 & 781.81 & 8.80 & 1.53 & 0.0124 \\
\hline$(M+H)+$ & N1-Methyl-2-pyridone-5-carboxamide & $\begin{array}{l}\text { Nicotinate and nicotinamide } \\
\text { metabolism }\end{array}$ & 153.07 & 127.37 & 1.36 & 1.32 & 0.0212 \\
\hline$(\mathrm{M}+\mathrm{Na})+$ & D-Mannose & Lysosome & 203.05 & 574.98 & 1.70 & 0.65 & 0.0314 \\
\hline$(M+H)+$ & L-Pyroglutamic acid & Glutathione metabolism & 130.05 & 751.76 & 1.85 & 0.65 & 0.0344 \\
\hline$(\mathrm{M}+\mathrm{Na})+$ & 1-Palmitoyl-sn-glycero-3-phosphocholine & - & 518.32 & 386.60 & 1.49 & 1.24 & 0.0575 \\
\hline$(\mathrm{M}-\mathrm{H}+2 \mathrm{Na})+$ & 1-Stearoyl-2-hydroxy-sn-glycero-3-phosphocholine & - & 568.34 & 367.11 & 4.30 & 1.74 & 0.0699 \\
\hline$(M+H)+$ & 5-Methylcytosine & Pyrimidine metabolism & 126.07 & 403.47 & 1.05 & 0.66 & 0.0741 \\
\hline$(M+H)+$ & $\begin{array}{l}\text { 1-Palmitoyl-2-hydroxy-sn-glycero-3- } \\
\text { phosphoethanolamine }\end{array}$ & - & 454.29 & 396.52 & 1.27 & 1.57 & 0.0790 \\
\hline $\begin{array}{l}(\mathrm{M}+\mathrm{H}- \\
\left.2 \mathrm{H}_{2} \mathrm{O}\right)+\end{array}$ & 2-Amino-2-methyl-1,3-propanediol & - & 70.06 & 541.31 & 1.15 & 0.78 & 0.0801 \\
\hline$(M+H)+$ & 2-Hydroxyadenine & Purine metabolism & 152.06 & 457.91 & 1.50 & 1.32 & 0.0813 \\
\hline$(M+H)+$ & Deoxycytidine & Pyrimidine metabolism & 228.10 & 421.57 & 1.02 & 0.74 & 0.0881 \\
\hline$(\mathrm{M}-\mathrm{H})-$ & L-Malic acid & Renal cell carcinoma & 133.01 & 727.91 & 1.80 & 1.85 & 0.0009 \\
\hline$(\mathrm{M}+\mathrm{Na}-2 \mathrm{H})-$ & 1-Oleoyl-L-alpha-lysophosphatidic acid & - & 457.23 & 438.26 & 1.67 & 1.63 & 0.0027 \\
\hline$(\mathrm{M}-\mathrm{H})-$ & 4-Nitrophenol & - & 138.02 & 59.08 & 1.05 & 0.82 & 0.0167 \\
\hline$(\mathrm{M}-\mathrm{H})-$ & Arachidonic acid & $\begin{array}{l}\text { Biosynthesis of unsaturated fatty } \\
\text { acids }\end{array}$ & 303.23 & 67.07 & 16.18 & 1.77 & 0.0170 \\
\hline$(\mathrm{M}-\mathrm{H})-$ & Stearic acid & $\begin{array}{l}\text { Biosynthesis of unsaturated fatty } \\
\text { acids }\end{array}$ & 283.26 & 349.68 & 1.11 & 1.58 & 0.0183 \\
\hline$(\mathrm{M}-\mathrm{H})-$ & Ketoisocaproic acid & $\begin{array}{l}\text { Valine, leucine and isoleucine } \\
\text { degradation }\end{array}$ & 129.06 & 94.17 & 5.75 & 1.20 & 0.0218 \\
\hline$(\mathrm{M}+\mathrm{Na}-2 \mathrm{H})-$ & Stavudine & - & 245.05 & 539.43 & 1.16 & 0.30 & 0.0281 \\
\hline$(\mathrm{M}-\mathrm{H})-$ & Hypoxanthine & Purine metabolism & 135.03 & 298.92 & 7.13 & 1.25 & 0.0335 \\
\hline$(\mathrm{M}-\mathrm{H})-$ & 9R,10S-EpOME & - & 295.23 & 75.32 & 1.46 & 1.68 & 0.0373 \\
\hline $\begin{array}{l}(\mathrm{M}+ \\
\left.\mathrm{CH}_{3} \mathrm{COO}\right)-\end{array}$ & Phosphorylcholine & Glycerophospholipid metabolism & 242.08 & 721.65 & 1.32 & 2.28 & 0.0387 \\
\hline$(\mathrm{M}-\mathrm{H})-$ & Succinate & Citrate cycle (TCA cycle) & 117.02 & 697.09 & 1.81 & 1.30 & 0.0409 \\
\hline$(\mathrm{M}-\mathrm{H})-$ & $\begin{array}{l}(4 Z, 7 Z, 10 Z, 13 Z, 16 Z, 19 Z)-4,7,10,13,16,19- \\
\text { Docosahexaenoic acid }\end{array}$ & $\begin{array}{l}\text { Biosynthesis of unsaturated fatty } \\
\text { acids }\end{array}$ & 327.23 & 67.13 & 8.88 & 1.87 & 0.0413 \\
\hline$(\mathrm{M}-\mathrm{H})-$ & Docosatrienoic acid & - & 333.28 & 64.84 & 1.15 & 1.44 & 0.0459 \\
\hline$(\mathrm{M}-\mathrm{H})-$ & Palmitic acid & $\begin{array}{l}\text { Biosynthesis of unsaturated fatty } \\
\text { acids }\end{array}$ & 255.23 & 89.61 & 7.25 & 2.51 & 0.0478 \\
\hline$(\mathrm{M}-\mathrm{H})-$ & Eicosapentaenoic acid & $\begin{array}{l}\text { Biosynthesis of unsaturated fatty } \\
\text { acids }\end{array}$ & 301.22 & 68.36 & 4.80 & 1.90 & 0.0505 \\
\hline$(\mathrm{M}-\mathrm{H})-$ & Dihomo-gamma-linolenic acid & - & 305.25 & 66.69 & 4.36 & 1.67 & 0.0543 \\
\hline$(\mathrm{M}-\mathrm{H})-$ & L-Ascorbic acid & Glutathione metabolism & 175.02 & 660.84 & 2.19 & 2.01 & 0.0617 \\
\hline$(\mathrm{M}-\mathrm{H})-$ & Norethindrone acetate & - & 339.20 & 1152.64 & 1.82 & 0.64 & 0.0852 \\
\hline$(\mathrm{M}-\mathrm{H})-$ & Glycocholic acid & Bile secretion & 464.31 & 322.78 & 1.41 & 1.43 & 0.0884 \\
\hline$(\mathrm{M}-\mathrm{H})^{-}$ & Nnamecis-9,10-epoxystearic acid & - & 297.24 & 75.71 & 1.42 & 1.82 & 0.0895 \\
\hline
\end{tabular}

${ }^{a}$ GF germ-free, $F A$ short chain fatty acids, M-to-Z mass-to-charge ratio, Rt retention time; the VIP value was obtained from OPLS-DA model with a threshold of 1.0; $F C$ foldchange, was calculated by dividing the mean intensity of FA group pig's serum metabolites by the mean intensity of GF group pig's serum metabolites; the significance $P$-value was obtained from Student's test with a threshold of 0.10 


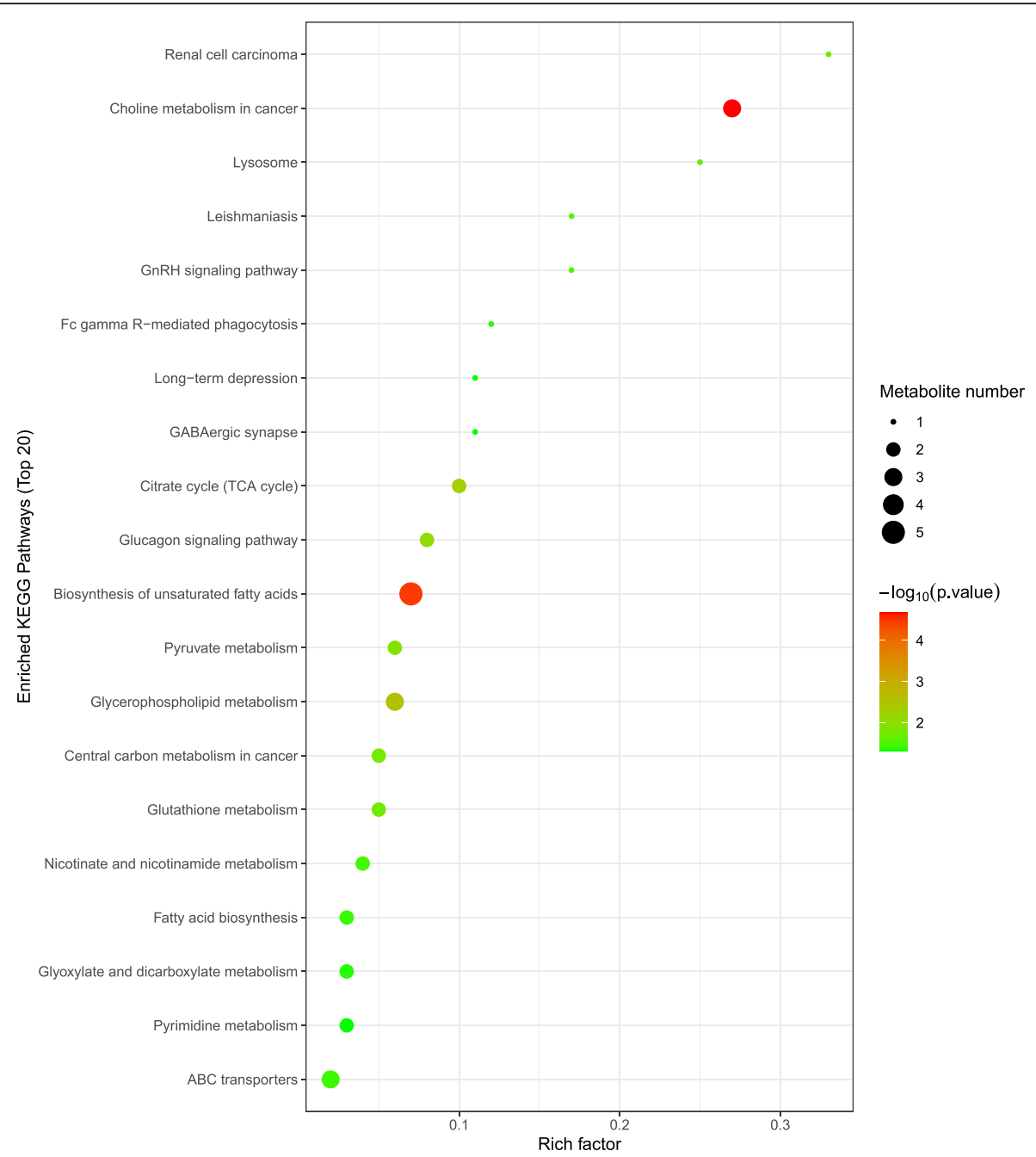

Fig. 5 Topology analysis of metabolic pathways identified between GF and FA groups. The X-axis represents the rich factor, and the Y-axis represents the pathway. Larger sizes and darker colors represent greater pathway enrichment and higher pathway impact values, respectively. GF, germ-free; FA, short chain fatty acids

pathway being involved in the regulation of lipid and glucose metabolism, adenosine monophosphateactivated protein kinase (AMPK) also plays an important role in this regulation. Accumulating evidence demonstrated that SCFAs could increase AMPK activity in the liver and muscle $[7,64]$. In the present study, the ratio of p-AMPK/AMPK was significantly increased in the FA group. Additionally, SCFAs were found to mediate liver lipid and glucose homeostasis via activating the PPARdependent AMPK-ACC pathway, which regulated the effects of SCFAs on gluconeogenesis and lipogenesis [8]. Of note, the present study observed the protein expression level of ACC in liver of the FA group tended to be higher than that in the GF group. These findings indicated that exogenous SCFAs may decrease fat storage and improve glucose control by binding to the GPR43 and activating the AMPK-ACC pathway in GF pigs.
To further understand the underlying mechanisms of SCFAs on lipid and glucose metabolism, metabolomics analysis was introduced in the present study. Metabolomics is a pyramidally used tool for exhaustive research of all metabolites comprised in an organism [65], which offers a novel strategy to identify the potential markers and to explore the molecular mechanisms and metabolic pathways response to specific nutritional interventions. Importantly, the serum can be regarded as a metabolic fingerprint that provides visual results of the metabolic differences and reveals the changes in metabolic pathways under various physiological or nutritional conditions [66]. In the present study, PLS-DA and OPLS-DA analyses demonstrated a clear separation of serum metabolites due to oral administration of SCFAs, suggesting marked differences in the metabolic profiles. Indeed, several fatty acids, such as stearic acid, arachidonic acid, 
docosahexaenoic acid, and palmitic acid in the FA group apparently increased compared with those in the GF group. Increases in serum fatty acids levels implied that lipid metabolisms have been altered. Taken KEGG pathway analysis, we observed these fatty acids (stearic acid, arachidonic acid, docosahexaenoic acid, palmitic acid) were involved in the biosynthesis of unsaturated fatty acids pathway. Of note, oral administration of SCFAs has the most significant impact on this metabolic pathway. Intake of unsaturated fatty acids, which consist of monounsaturated fatty acids and polyunsaturated fatty acids, has been associated with favorable cardiac diastolic function and body composition in obese patients [67]. Moreover, increasing unsaturated fatty acids in the diet also prevented weight gain and cardiac dysfunction in a mouse model [68]. Consequently, these suggested that exogenous introduction of SCFAs may alleviate the lipid deposition via activating the metabolic pathway of biosynthesis of unsaturated fatty acids in GF pigs.

\section{Conclusions}

In summary, this study demonstrated that SCFAs may attenuate fat deposition and to some extent improve glucose control in the liver and longissimus dorsi, which occur independently of the gut microbiota. The possible mechanisms of exogenous SCFAs on lipid reduction and glucose tolerance improvement may be via binding to the GPR43 and activating the AMPK-ACC pathway, and stimulating the metabolic pathway of biosynthesis of unsaturated fatty acids in GF pigs. The current work further suggested the importance of the presence of gut microbes and provided novel evidence that exogenous introduction of SCFAs may be a possible therapeutic strategy to prevent metabolic disorders and to counteract the gut microbiota deficiency or imbalance.

\footnotetext{
Abbreviations

ACC: Acetyl-CoA carboxylase; AMPK: Adenosine monophosphate-activated protein kinase; ANGPTL4: Angiopoietin-like 4; CD36: Fatty acid transporter CD36; CPT-1B: Carnitine palmitoyltransferase 1 B; FAS: Fatty acid synthase; FOXO-1: Foxo1 forkhead box 01; G6PC: Glucose-6-phosphatase; GF: Germfree; GLU-2: Glucose transporter 2; GPR43: G-protein-coupled receptors 43; GSK3: Glycogen synthase kinase 3; GYS2: Glycogen synthase 2; HDL-c: High density lipoprotein-cholesterol; HL: Hepatic lipase; INSR: Insulin receptor; IRS1: Insulin receptor substrate 1; LDL-c: Low density lipoprotein-cholesterol; LPL: Lipoprotein lipase; MDH: Malate dehydrogenase; OPLS-DA: Orthogonal partial least squares discriminant analysis; P-AMPK: Phosphorylated adenosine monophosphate-activated protein kinase; PCK1: Phosphoenolpyruvate carboxykinase 1; PIK3: Phosphatidylinositol 3-kinase catalytic subunit type 3: PGC-1a: Peroxisome proliferator-activated receptor gamma coactivator-1a; PLS-DA: Partial least squares discriminant analysis; PNPLA2: Adipose triglyceride lipase; PPAR- $\gamma$ : Peroxisome proliferator-activated receptor gamma; PRKAA1: AMP activated alpha 1; PRKAA2: AMP activated alpha 2; Sirt1: Silent information regulator 1 ; SREBP-1C: Sterol regulatory element binding protein 1C; TC: Total cholesterol; TG: Triglyceride; UHPLC-Q-TOF/MS: Ultrahighperformance liquid chromatography equipped with quadrupole time offlight mass spectrometry; VIP: Variable importance in the projection
}

\section{Supplementary Information}

The online version contains supplementary material available at https://doi. org/10.1186/s40104-021-00581-3.

Additional file 1 : Table S1. Ingredient composition of the milk powder (as-fed basis). Table S2. Ingredient composition of the basal diet (as-fed basis). Table S3. Infusion volume of sterile saline or SCFAs mixture for each pig per day. Table S4. Primer sequences used for realtime quantitative PCR.

\section{Acknowledgements \\ Not applicable.}

\section{Authors' contributions}

H.Z. conducted the animal work and the laboratory work, and wrote the manuscript. H.Z., L.G. and D.C. designed the experiment. B.Y. and J.S. gave advice on the experiment design. H.Z. analyzed the study data and wrote the manuscript. Z.L. and H.C. helped to revise the manuscript. All the authors have read and approved the final manuscript.

\section{Funding}

This study was supported by National Natural Science Foundation of China (31730091) and the National Key Research and Development Program of China (2017YFD0500503).

\section{Availability of data and materials}

The data were exhibited in the main manuscript and supplemental materials.

\section{Declarations}

Ethics approval and consent to participate

Experimental protocols and procedures used in the present experiment were approved by the Animal Care and Use Committee of Sichuan Agricultural University (Chengdu, China) under permit number DKY-B20131704.

\section{Consent for publication}

Not applicable.

\section{Competing interests}

The authors declare that they have no conflict of interest.

\section{Author details}

${ }^{1}$ Key Laboratory of Animal Disease-Resistance Nutrition, Chengdu 611130 Sichuan, China. ${ }^{2}$ Animal Nutrition Institute, Sichuan Agricultural University, Chengdu 611130, Sichuan, China. ${ }^{3}$ Key Laboratory of Pig Industry Sciences, Rongchang 402460, Chongqing, China. ${ }^{4}$ Chongqing Academy of Animal Sciences, Rongchang 402460, Chongqing, China. ${ }^{5}$ College of Food Science, Sichuan Agricultural University, Ya'an 625014, Sichuan, China.

Received: 2 November 2020 Accepted: 8 March 2021

Published online: 06 May 2021

\section{References}

1. Delzenne NM, Cani PD, Everard A, Neyrinck AM, Bindels LB. Gut microorganisms as promising targets for the management of type 2 diabetes. Diabetologia. 2015;58(10):2206-17. https://doi.org/10.1007/s00125015-3712-7.

2. Canfora EE, Jocken JW, Blaak EE. Short-chain fatty acids in control of body weight and insulin sensitivity. Nat Rev Endocrinol. 2015;11(10):577-91. https://doi.org/10.1038/nrendo.2015.128.

3. DeVadder F, Kovatcheva-Datchary P, Zitoun C, Duchampt A, Bäckhed F, Mithieux G. Microbiota-produced succinate improves glucose homeostasis via intestinal gluconeogenesis. Cell Metab. 2016;24(1):151-7. https://doi. org/10.1016/j.cmet.2016.06.013.

4. Byrne CS, Chambers ES, Morrison DJ, Frost G. The role of short chain fatty acids in appetite regulation and energy homeostasis. Int J Obes. 2015;39(9): 1331-8. https://doi.org/10.1038/ijo.2015.84.

5. DeVadder F, Kovatcheva-Datchary P, Goncalves D, Vinera J, Zitoun C, Duchampt A, et al. Microbiota-generated metabolites promote metabolic 
benefits via gut-brain neural circuits. Cell. 2014;156(1-2):84-96. https://doi. org/10.1016/j.cell.2013.12.016.

6. Sahuri-Arisoylu M, Brody LP, Parkinson JR, Parkes H, Navaratnam N, Miller $A D$, et al. Reprogramming of hepatic fat accumulation and 'browning' of adipose tissue by the short-chain fatty acid acetate. Int J Obes. 2016;40(6): 955-63. https://doi.org/10.1038/ijo.2016.23.

7. Gao Z, Yin J, Zhang J, Ward RE, Martin RJ, Lefevre M, et al. Butyrate improves insulin sensitivity and increases energy expenditure in mice. Diabetes. 2009;58(7):1509-17. https://doi.org/10.2337/db08-1637.

8. den Besten G, Bleeker A, Gerding A, van Eunen K, Havinga R, van Dijk TH, et al. Short-chain fatty acids protect against high-fat diet-induced obesity via a PPARY-dependent switch from lipogenesis to fat oxidation. Diabetes. 2015;64(7):2398-408. https://doi.org/10.2337/db14-1213.

9. Jiao AR, Diao H, Yu B, He J, Yu J, Zheng P, et al. Oral administration of short chain fatty acids could attenuate fat deposition of pigs. PLoS One. 2018; 13(5):e0196867. https://doi.org/10.1371/journal.pone.0196867.

10. Jiao A, Yu B, He J, Yu J, Zheng P, Luo Y, et al. Short chain fatty acids could prevent fat deposition in pigs via regulating related hormones and genes. Food Funct. 2020;11(2):1845-55. https://doi.org/10.1039/C9FO02585E.

11. Canfora EE, van der Beek CM, Jocken JWE, Goossens GH, Holst JJ, Olde Damink SWM, et al. Colonic infusions of short-chain fatty acid mixtures promote energy metabolism in overweight/obese men: a randomized crossover trial. Sci Rep. 2017;7(1):2360. https://doi.org/10.1038/s41598-017-02 546-x.

12. Turnbaugh PJ, Ley RE, Mahowald MA, Magrini V, Mardis ER, Gordon JI. An obesity-associated gut microbiome with increased capacity for energy harvest. Nature. 2006;444(7122):1027-31. https://doi.org/10.1038/na ture05414.

13. Perry RJ, Peng L, Barry NA, Cline GW, Zhang D, Cardone RL, et al. Acetate mediates a microbiome-brain- $\beta$-cell axis to promote metabolic syndrome. Nature. 2016;534(7606):213-7. https://doi.org/10.1038/nature18309.

14. Lambeth SM, Carson T, Lowe J, Ramaraj T, Leff JW, Luo L, et al. Composition, diversity and abundance of gut microbiome in prediabetes and type 2 diabetes. J Diabetes Obes. 2015;2(3):1-7. https://doi.org/10.1543 6/2376-0949.15.031.

15. Menni C, Lin C, Cecelja M, Mangino M, Matey-Hernandez ML, Keehn L, et al. Gut microbial diversity is associated with lower arterial stiffness in women. Eur Heart J. 2018;39(25):2390-7. https://doi.org/10.1093/eurheart//ehy226.

16. Goodrich JK, Waters JL, Poole AC, Sutter JL, Koren O, Blekhman R, et al. Human genetics shape the gut microbiome. Cell. 2014;159(4):789-99. https://doi.org/10.1016/j.cell.2014.09.053.

17. Beaumont M, Goodrich JK, Jackson MA, Yet I, Davenport ER, Vieira-Silva S, et al. Heritable components of the human fecal microbiome are associated with visceral fat. Genome Biol. 2016;17(1):189. https://doi.org/10.1186/s13 059-016-1052-7.

18. Furet JP, Kong LC, Tap J, Poitou C, Basdevant A, Bouillot JL, et al. Differential adaptation of human gut microbiota to bariatric surgery-induced weight loss: links with metabolic and low-grade inflammation markers. Diabetes. 2010;59(12):3049-57. https://doi.org/10.2337/db10-0253.

19. Moran CP, Shanahan F. Gut microbiota and obesity: role in aetiology and potential therapeutic target. Best Pract Res Clin Gastroenterol. 2014;28(4): 585-97. https://doi.org/10.1016/.jppg.2014.07.005.

20. Delzenne NM, Cani PD. Interaction between obesity and the gut microbiota: relevance in nutrition. Annu Rev Nutr. 2011;31:1-7.

21. Meyer R, Bohl E, Kohler E. Procurement and maintenance of germ-free swine for microbiological investigations. Appl Microbiol. 1964;12(4):295-300. https://doi.org/10.1128/AM.12.4.295-300.1964.

22. Meurens FO, Summerfield A, Nauwynck H, Saif L, Gerdts V. The pig: a model for human infectious diseases. Trends Microbiol. 2012;20(1):50-7. https://doi. org/10.1016/j.tim.2011.11.002

23. Odle J, Lin X, Jacobi SK, Kim SW, Stahl CH. The suckling piglet as an agrimedical model for the study of pediatric nutrition and metabolism. Annu Rev Anim Biosci. 2011;2:419-44.

24. Chen J, Li Y, Yu B, Chen D, Mao X, Zheng P, et al. Dietary chlorogenic acid improves growth performance of weaned pigs through maintaining antioxidant capacity and intestinal digestion and absorption function. J Anim Sci. 2018;96(3):1108-18. https://doi.org/10.1093/jas/skx078.

25. Pfaffl MW. A new mathematical model for relative quantification in real-time RT-PCR. Nucleic Acids Researc. 2001;29:900-5.

26. Suryawan A, Nguyen HV, Bush JA, Davis TA. Developmental changes in the feeding-induced activation of the insulin-signaling pathway in neonatal pigs. Am J Physiol Endocrinol Metab. 2001;281(5):E908-15. https://doi.org/1 0.1152/ajpendo.2001.281.5.E908.

27. Hu L, Che L, Wu C, Curtasu MV, Wu F, Fang Z. Metabolomic profiling reveals the difference on reproductive performance between high and low lactational weight loss sows. Metabolomics. 2019;9:295.

28. Chambers MC, Maclean B, Burke R, Amodei D, Ruderman DL, Neumann S, et al. A cross-platform toolkit for mass spectrometry and proteomics. Nat Biotechnol. 2012;30(10):918-20. https://doi.org/10.1038/nbt.2377.

29. Jia H, Shen X, Guan Y, Xu M, Tu J, Mo M, et al. Predicting the pathological response to neoadjuvant chemoradiation using untargeted metabolomics in locally advanced rectal cancer. Radiother Oncol. 2018;128(3):548-56. https://doi.org/10.1016/j.radonc.2018.06.022.

30. Wang H, Liu Z, Wang S, Cui D, Zhang X, Liu Y, Zhang Y. UHPLC-Q-TOF/MS based plasma metabolomics reveals the metabolic perturbations by manganese exposure in rat models. Metallomics. 2017;9(2):192-203. https:/ doi.org/10.1039/C7MT00007C.

31. Feng JH, Wu HF, Chen Z. Metabolic responses of HeLa cells to silica nanoparticles by NMR-based metabolomic analyses. Metabolomics. 2013; 9(4):874-86. https://doi.org/10.1007/s11306-013-0499-8.

32. Dervishi E, Zhang G, Dunn SM, Mandal R, Wishart DS, Ametaj BN. GC-MS metabolomics identifies metabolite alterations that precede subclinical mastitis in the blood of transition dairy cows. J Proteome Res. 2016;16(2): 433-46. https://doi.org/10.1021/acs.jproteome.6b00538.

33. Zhou H, Sun J, Ge L, Liu Z, Chen H, Yu B, Chen D. Exogenous infusion of short-chain fatty acids can improve intestinal functions independently of the gut microbiota. J Anim Sci. 2020;98(12). https:// doi.org/10.1093/jas/skaa371.

34. Petia KD, Anne N, Rozita A, Ying SL, Filipe DV, Tulika A, et al. Dietary fiberinduced improvement in glucose metabolism is associated with increased abundance of prevotella. Cell Metab. 2015;22:971-82.

35. Liu S, Willett W, Manson J, Hu F, Rosner B, Colditz G. Relation between changes in intakes of dietary fiber and grain products and changes in weight and development of obesity among middle-aged women. Am J Clin Nutr. 2003;78(5):920-7. https://doi.org/10.1093/ajcn/78.5.920.

36. Høverstad T, Midtvedt T. Short-chain fatty acids in germfree mice and rats. J Nutr. 1986;116(9):1772-6. https://doi.org/10.1093/jn/116.9.1772.

37. Liu M, Liu F. Regulation of adiponectin multimerization, signaling and function. Best Pract Res Clin Endocrinol Metab. 2014;28(1):25-31. https://doi. org/10.1016/j.beem.2013.06.003.

38. Arita Y, Kihara S, Ouchi N, Takahashi M, Maeda K, Miyagawa J, et al. Paradoxical decrease of an adipose-specific protein, adiponectin, in obesity. Biochem Biophys Res Commun. 1999;257(1):79-83. https://doi.org/10.1006/ bbrc.1999.0255.

39. Snel M, Jonker JT, Schoones J, Lamb H, Jazet IM. Ectopic fat and insulin resistance: pathophysiology and effect of diet and lifestyle interventions. Int J Endocrinol. 2012;7:983814.

40. Bäckhed F, Manchester JK, Semenkovich CF, Gordon Jl. Mechanisms underlying the resistance to diet-induced obesity in germ-free mice. Proc Natl Acad Sci U S A. 2007;104(3):979-84. https://doi.org/10.1073/pnas.0605374104.

41. Bäckhed F, Ding H, Wang T, Hooper LV, Koh GY, Nagy A, et al. The gut microbiota as an environmental factor that regulates fat storage. Proc Natl Acad Sci U S A. 2004;101(44):15718-23. https://doi.org/10.1073/pnas.04 07076101.

42. Yu S, Ren E, Xu J, Su Y, Zhu W. Effects of early intervention with sodium butyrate on lipid metabolism-related gene expression and liver metabolite profiles in neonatal piglets. Livest Sci. 2017;195:80-6. https://doi.org/10.101 6/.j.livsci.2016.11.013.

43. Yan H, Zheng P, Yu B, Yu J, Mao X, He J, Huang Z, Chen D. Postnatal highfat diet enhances ectopic fat deposition in pigs with intrauterine growth retardation. Eur J Nutr. 2017;56(2):483-90. https://doi.org/10.1007/s00394-01 5-1093-9.

44. Kim KH. Regulation of mammalian acetyl-coenzyme A carboxylase. Annu Rev Nutr. 2003;17:77-99.

45. Shimomura I, Bashmakov Y, Ikemoto S, Horton JD, Brown MS, Goldstein JL. Insulin selectively increases SREBP-1c mRNA in the livers of rats with streptozotocin-induced diabetes. Proc Natl Acad Sci U S A. 1999;96(24): 13656-61. https://doi.org/10.1073/pnas.96.24.13656.

46. Febbraio M, Hajjar DP, Silverstein RL. CD36: a class B scavenger receptor involved in angiogenesis, atherosclerosis, inflammation, and lipid metabolism. J Clin Invest. 2001;108(6):785-91. https://doi.org/10.1172/ JCl14006. 
47. Bonen A, Parolin ML, Steinberg GR, Calles-Escandon J, Tandon NN, Glatz JF, et al. Triacylglycerol accumulation in human obesity and type 2 diabetes is associated with increased rates of skeletal muscle fatty acid transport and increased sarcolemmal FAT/CD36. FASEB J. 2004;18(10):1144-6. https://doi. org/10.1096/fj.03-1065fje.

48. Vega RB, Huss JM, Kelly DP. The coactivator PGC-1 cooperates with peroxisome proliferator-activated receptor alpha in transcriptional control of nuclear genes encoding mitochondrial fatty acid oxidation enzymes. Mol Cell Biol. 2000;20(5):1868-76. https://doi.org/10.1128/ MCB.20.5.1868-1876.2000.

49. Balampanis K, Chasapi A, Kourea E, Tanoglidi A, Hatziagelaki E, Lambadiari V, et al. Inter-tissue expression patterns of the key metabolic biomarker PGC$1 a$ in severely obese individuals: implication in obesity-induced disease. Hell J Cardiol. 2019;60(5):282-93. https://doi.org/10.1016/j.hjc.2018.08.002.

50. Kimura I, Inoue D, Maeda T, Hara T, Ichimura A, Miyauchi S, et al. Shortchain fatty acids and ketones directly regulate sympathetic nervous system via G protein-coupled receptor 41 (GPR41). Proc Natl Acad Sci U S A. 2011; 108(19):8030-5. https://doi.org/10.1073/pnas.1016088108.

51. Wasserman DH. Four grams of glucose. Am J Physiol Endocrinol Metab. 2009;296(1):E11-21. https://doi.org/10.1152/ajpendo.90563.2008.

52. Agius L. Physiological control of liver glycogen metabolism: lessons from novel glycogen phosphorylase inhibitors. Mini Rev Med Chem. 2010;10(12): 1175-87. https://doi.org/10.2174/1389557511009011175.

53. Irimia JM, Meyer CM, Peper CL, Zhai L, Bock CB, Previs SF, et al. Impaired glucose tolerance and predisposition to the fasted state in liver glycogen synthase knock-out mice. J Biol Chem. 2010;285(17):12851-61. https://doi. org/10.1074/jbc.M110.106534

54. Petersen KF, Dufour S, Savage DB, Bilz S, Solomon G, Yonemitsu S, et al. The role of skeletal muscle insulin resistance in the pathogenesis of the metabolic syndrome. Proc Natl Acad Sci U S A. 2007;104(31):12587-94. https://doi.org/10.1073/pnas.0705408104.

55. Ros S, Zafra D, Valles-Ortega J, García-Rocha M, Forrow S, Domínguez J, et al. Hepatic overexpression of a constitutively active form of liver glycogen synthase improves glucose homeostasis. J Biol Chem. 2010; 285(48):37170-7. https://doi.org/10.1074/jbc.M110.157396.

56. Chambers ES, Viardot A, Psichas A, Morrison DJ, Murphy KG, Zac-Varghese $\mathrm{SE}$, et al. Effects of targeted delivery of propionate to the human colon on appetite regulation, body weight maintenance and adiposity in overweight adults. Gut. 2015;64(11):1744-54. https://doi.org/10.1136/gutjnl-2014-307913.

57. Wood IS, Trayhurn P. Glucose transporters (GLUT and SGLT): expanded families of sugar transport proteins. Br J Nutr. 2003;89(1):3-9. https://doi. org/10.1079/BJN2002763.

58. Narasimhan A, Chinnaiyan M, Karundevi B. Ferulic acid regulates hepatic GLUT2 gene expression in high fat and fructose-induced type-2 diabetic adult male rat. Eur J Pharmacol. 2015;761:391-7. https://doi.org/10.1016/j. ejphar.2015.04.043.

59. Maslowski KM, Vieira AT, Ng A, Kranich J, Sierro F, Yu D, et al. Regulation of inflammatory responses by gut microbiota and chemoattractant receptor GPR43. Nature. 2009;461(7268):1282-6. https://doi.org/10.1038/nature08530.

60. Samuel BS, Shaito A, Motoike T, Rey FE, Backhed F, Manchester JK, et al. Effects of the gut microbiota on host adiposity are modulated by the shortchain fatty-acid binding $G$ protein-coupled receptor, Gpr41. Proc Natl Acad Sci U S A. 2008;105(43):16767-72. https://doi.org/10.1073/pnas.0808567105.

61. Ichimura A, Hirasawa A, Hara T, Tsujimoto G. Free fatty acid receptors act as nutrient sensors to regulate energy homeostasis. Prostaglandins Other Lipid Mediat. 2009;89(3-4):82-8. https://doi.org/10.1016/j.prostaglandins.2009.05.003.

62. Kimura I, Ozawa K, Inoue D, Imamura T, Kimura K, Maeda T, et al. The gut microbiota suppresses insulin-mediated fat accumulation via the short-chain fatty acid receptor GPR43. Nat Commun. 2013;4(1):1829. https://doi.org/10.1 038/ncomms2852.

63. Tang C, Ahmed K, Gille A. Loss of FFA2 and FFA3 increases insulin secretion and improves glucose tolerance in type 2 diabetes. Nat Med. 2015;21(2): 173-7. https://doi.org/10.1038/nm.3779.

64. Hiromi Y, Katsuhiko F, Erina I, Seika I, Nobuyo K, Kimoto M, et al. Improvement of obesity and glucose tolerance by acetate in type 2 diabetic Otsuka Long-Evans Tokushima Fatty (OLETF) rats. Biosci Biotechnol Biochem. 2007;71:1236-43

65. Lau SK, Lam CW, Curreem SO, Lee KC, Lau CC, Chow WN, et al. Identification of specific metabolites in culture supernatant of mycobacterium tuberculosis using metabolomics: exploration of potential biomarkers. Emerg Microbes Infect. 2015;4:e6.
66. Ramsay TG, Stoll MJ, Shannon AE, Blomberg LA. Metabolomic analysis of longissimus from underperforming piglets relative to piglets with normal preweaning growth. J Anim Sci Biotechnol. 2018;9(1):36. https://doi.org/1 0.1186/s40104-018-0251-3.

67. Carbone S, Canada JM, Buckley LF, Trankle CR, Billingsley HE, Dixon DL, et al. Dietary fat, sugar consumption, and cardiorespiratory fitness in patients with heart failure with preserved ejection fraction. JACC Basic Transl Sci. 2017; 2(5):513-25. https://doi.org/10.1016/j.jacbts.2017.06.009.

68. Carbone S, Mauro AG, Mezzaroma E, Kraskauskas D, Marchetti C, Buzzetti R, et al. A high-sugar and high-fat diet impairs cardiac systolic and diastolic function in mice. Int J Cardiol. 2015;198:66-9. https://doi.org/10.1016/j.ijca rd.2015.06.136.
Ready to submit your research? Choose BMC and benefit from:

- fast, convenient online submission

- thorough peer review by experienced researchers in your field

- rapid publication on acceptance

- support for research data, including large and complex data types

- gold Open Access which fosters wider collaboration and increased citations

- maximum visibility for your research: over $100 \mathrm{M}$ website views per year

At BMC, research is always in progress.

Learn more biomedcentral.com/submissions 